Check for updates

Cite this: Mater. Chem. Front., 2020, 4, 206

Received 1st October 2019,

Accepted 8th November 2019

DOI: $10.1039 / c 9 q m 00605 b$

rsc.li/frontiers-materials

\title{
Efficient as-cast thick film small-molecule organic solar cell with less fluorination on the donor
}

\author{
Kai Wang, $\ddagger^{\mathrm{a}}$ Xin Song, (D) $\ddagger^{\mathrm{b}}$ Xiao Guo, ${ }^{a}$ Yunhao Wang, ${ }^{\mathrm{a}}$ Xue Lai, ${ }^{\text {ac }}$ \\ Fei Meng, ${ }^{\text {ac }}$ Mengzhen Du, ${ }^{a}$ Dongyu Fan, ${ }^{a}$ Ren Zhang, ${ }^{a}$ Gongqiang Li, (D) *a \\ Aung Ko Ko Kyaw, (D)*c Jianpu Wang, ${ }^{a}$ Wei Huang ${ }^{\text {ad }}$ and Derya Baran (D) *b
}

\begin{abstract}
Herein, two donor materials based on fluorine substituted isatin units (DI3T-1F, DI3T-2F) were designed and synthesized for thick-film small molecule solar cells. The devices based on DI3T-1F demonstrate balanced charge transport and less trap-assisted recombination, leading to higher power conversion efficiency (PCE) of $8.33 \%$ with a thickness ca. $150 \mathrm{~nm}$ compared to DI3F-2F (PCE of 7.32\% with thick film at ca. $160 \mathrm{~nm}$ ) without additives, solvent or thermal annealing treatments. More interestingly, the device based on DI3T-1F small molecules demonstrates good tolerance to active layer thickness from 150 to $300 \mathrm{~nm}$ with device performance over $5 \%$. Our results indicate that less fluorine atoms on the donor units can optimize the charge transport, and phase-segregated morphology in small molecule solar cells without the need for post-treatment.
\end{abstract}

\section{Introduction}

Organic solar cells (OSCs) have attracted significant attention owing to their advantages of light weight, mechanical flexibility and large-area solution processibility. ${ }^{1-4}$ In the past several years, the OSC field has witnessed much progress with high power conversion efficiencies (PCEs) of over $16 \%{ }^{5}$ achieved in a single-junction configuration with a polymer donor on a laboratory scale. Yet, some of the drawbacks of polymer donors still limit the reproducible scale-up, such as batch-to-batch variation and material purification. Compared with their polymer counterparts, all small molecule solar cells (SMSCs) show more potential for industrialization because of their well-defined molecule structures, reproducible synthesis, and easy purification. ${ }^{6-10}$ With the continuous endeavors of molecule design and synthesis, the

\footnotetext{
${ }^{a}$ Key Laboratory of Flexible Electronic (KLOFE) \& Institute of Advanced Materials (IAM), Jiangsu National Synergistic Innovation Center for Advanced Materials (SICAM), Nanjing Tech University (NanjingTech), 30 South Puzhu Road, Nanjing 211816, P. R. China. E-mail: iamgqli@njtech.edu.cn

${ }^{b}$ King Abdullah University of Science and Technology (KAUST), KAUST Solar Center (KSC), Physical Sciences and Engineering Division (PSE), Thuwal, 23955-6900, Saudi Arabia.E-mail: derya.baran@kaust.edu.sa

${ }^{c}$ Guangdong University Key Laboratory for Advanced Quantum Dot Displays and Lighting, Shenzhen Key Laboratory for Advanced Quantum Dot Displays and Lighting, and Department of Electrical \& Electronic Engineering, Southern University of Science and Technology, Shenzhen 518055, P. R. China. E-mail: aung@sustech.edu.cn

${ }^{d}$ Shaanxi Institute of Flexible Electronics (SIFE), Northwestern Polytechnical University (NPU), 127 West Youyi Road, Xi'an 710072, China

$\dagger$ Electronic supplementary information (ESI) available. See DOI: 10.1039/c9qm00605b \# These authors contributed equally.
}

PCEs of SMSCs are reported to be over $12 \%,{ }^{11,12}$ with the blend of fused-ring electron acceptors.

Although significant progress has been achieved in SMSCs, blend morphology optimization methods such as thermal annealing, ${ }^{13-16}$ solvent annealing ${ }^{16-20}$ or trace amount of solvent additive $^{21-24}$ are still essential to improve efficiencies, because of the control of aggregation. These tedious methods would induce extremely low device reproducibility as it is challenging to finely control the morphologies of the film within a few seconds. The thickness of the active layer of SMSCs typically lies below $100 \mathrm{~nm}^{25}$ (normally 60-80 nm), which is unfavorable for largearea fabrication technologies, such as roll-to-roll coating, and printing techniques. ${ }^{26}$ In contrast, thick-film polymer solar cells have been widely explored by several strategies. These include: (1) enhancing the molecular crystallinity by extending the conjugated backbone; $;^{27,28}$ (2) adding a third component; ${ }^{29}$ and (3) tuning the dipole monents and steric hindrance of polymers or non-fullerene acceptors. ${ }^{30-32}$ Inspired by these strategies to improve the performance of polymer-containing devices, we seek to employ such methods for all-small-molecule solar cells.

In 2018, our group developed a small molecule donor DI3T-2F with di-fluorine substituted isatin ( $1 H$-indole-2,3-dione) as a peripheral unit, ${ }^{33}$ and the as-cast devices based on the DI3T-2F: $\mathrm{PC}_{71} \mathrm{BM}$ blend obtained a champion performance of $7.8 \%$ with a thick active layer $(\sim 150 \mathrm{~nm})$. However, thicker DI3T-2F based devices deliver only a moderate PCE (lower than 4\%) due to charge recombination issues in the thick films. Another problem with DI3T-2F is the too strong intermolecular interaction because of the formation of $\mathrm{F} \cdots \mathrm{H}, \mathrm{F} \cdots \mathrm{S}$, and $\mathrm{F} \cdots \mathrm{O}$ bonds, which results in its low miscibility with fullerene derivatives $\left(\mathrm{PC}_{71} \mathrm{BM}\right)$ and 

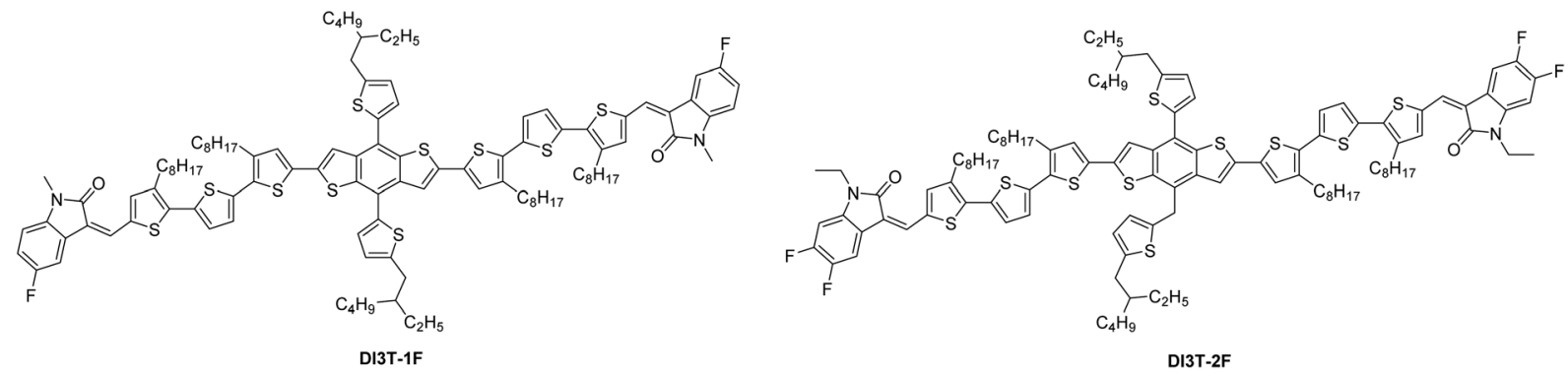

Scheme 1 Structures of DI3T-1F and DI3T-2F.

further coarse blend morphology in thick film devices. So decreasing the numbers of fluorine atoms on the peripheral isatin units can be adopted as a promising strategy to reduce the excessive donor-acceptor intermolecular interactions to optimize the morphology and thus give better performance.

Thus, we synthesized DI3T-1F (Scheme 1), and investigated the comparison to DI3T-2F based on DI3T-1F:PC ${ }_{71} \mathrm{BM}$ and DI3T-2F:PC ${ }_{71} \mathrm{BM}$ devices. As a result, the PCE of devices based on DI3T-1F was $8.33 \%$ without any pre or post device treatment, which represented a $14 \%$ improvement compared with that of the devices based on DI3T-2F (7.32\%). More interestingly, after a systematic study, DI3T-1F featured more balanced charge transport and suppressed trap-assisted recombination behavior compared to that of DI3T-2F devices, and the DI3T-1F devices yielded a champion PCE of $7.8 \%$ with an active layer thickness of $200 \mathrm{~nm}$, and even with a thickness of $300 \mathrm{~nm}$, the PCE is still as high as $5.43 \%$. These obvious differences manifest that our mono-fluorine strategy provides a fascinating approach for the construction of all-small-molecule solar cells with as-cast thick films.

\section{Results and discussion}

\section{Synthesis and material properties}

DI3T-1F and DI3T-2F were synthesized via Knoevenagel condensation from the dialdehyde intermediate 3 TBDTT $^{33}$ and the corresponding commercially available fluorination substituted oxindole derivatives in good yields as shown in Scheme S1 and the detailed synthesis procedure is described in the ESI. $\dagger$ Both structures were determined by NMR (Fig. S7 and S8, ESI $\dagger$ ). As expected, DI3T-1F exhibits a much better solubility than DI3T-2F in common organic solvents (dichloromethane and chloroform) due to weaker intermolecule intereaction, which is beneficial for easy-processability, specifically in thick-film device fabrication.

The optical properties of the two donors were investigated by UV-vis absorption spectra for solution in chloroform and film conditions (Fig. 1a). DI3T-1F and DI3T-2F can be classified as medium bandgap materials since the absorption onsets of the two donors are over $700 \mathrm{~nm}$. Although the two molecules show very similar UV-vis absorption in solution, there are still some differences in their thin films. The absorption maximum peak featured a slightly larger red-shift of approximately $10 \mathrm{~nm}$ in DI3T-1F, indicating a better self-assembly property from
DI3T-2F to DI3T-1F. ${ }^{34}$ Moreover, DI3T-1F displays an obvious vibronic shoulder peak, suggesting the stronger interchain aggregation in the film. ${ }^{35}$ Likewise, we determined the energy levels of DI3T-1F by cyclic voltammetry (CV) in DCM solution (Fig. S1, ESI $\dagger$ ) and all detailed optical and electrochemical data are summarized in Table 1. According to the theoretical calculations, the highest occupied molecular orbital (HOMO) is mainly stationed in the electron-donating core, while the lowest unoccupied molecular orbital (LUMO) is delocalized across the entire molecule. In this study, the middle skeleton is kept and the slight end group modification (from $1 \mathrm{~F}$ to $2 \mathrm{~F}$ ) would push the HOMO energetic level down, which is directly related to the $V_{\text {oc }}$ of the final OSC devices (which will be shown in the next part).

Differential scanning calorimetry (DSC) was carried out to verify the crystallinity of our DI3T-1F (Fig. S2, ESI $\dagger$ ). DI3T-1F displayed a melting point $\left(T_{\mathrm{m}}\right)$ at $182{ }^{\circ} \mathrm{C}$, whereas the DI3T-2F exhibits a $T_{\mathrm{m}}$ at $192{ }^{\circ} \mathrm{C}$, indicating the strong fluorination effect and thus crystallinity of these two small molecules. Thermogravimetric analysis (TGA) shows that DI3T-1F possesses a 5\% weight loss at $371{ }^{\circ} \mathrm{C}$, exhibiting an excellent thermal stability for constructing the solar cell devices.

\section{Device characterization and performance analysis of SM-OSCs}

To investigate the effect of the terminal unit on the photovoltaic properties of the fullerene solar cells, two devices of DI3T1F:PC ${ }_{71} \mathrm{BM}$ and DI3T-2F:PC ${ }_{71} \mathrm{BM}$ were fabricated with a conventional configuration of ITO/PEDOT:PSS/active layer/Phen$\mathrm{NaDPO} / \mathrm{Al},{ }^{36,37}$ where PEDOT:PSS used as a hole-transporting layer and PhenNa-DPO as an electron-transporting layer.

Moreover, since DI3T-1F and DI3T-2F have a higher solubility in CF than other solvents, CF was selected as the spincoating solvent for the two binary systems. In our previous report, the DI3T-2F:PC71BM system can obtain impressive performance with a $\mathrm{D}: \mathrm{A}$ ratio of $2: 1$ without any pre and post-treatment. Herein, we cultivate the same device fabrication condition as a control device. DI3T-2F:PC ${ }_{71} \mathrm{BM}$ devices presented a champion performance of $7.32 \%$ with an opencircuit voltage of $835 \mathrm{mV}$, short-circuit current density $\left(J_{\mathrm{sc}}\right)$ of $12.8 \mathrm{~mA} \mathrm{~cm}^{-2}$, and fill factor (FF) of $68.5 \%$, which is similar to our previous results. While fabricating with DI3T-1F:PC71BM, the corresponding devices exhibited better photovoltaic performance of $8.33 \%$ with $V_{\text {oc }}$ of $815 \mathrm{mV}, J_{\mathrm{sc}}$ of $13.6 \mathrm{~mA} \mathrm{~cm}^{-2}$, and $\mathrm{FF}$ of $75.1 \%$, and such a performance enhancement originated 
a

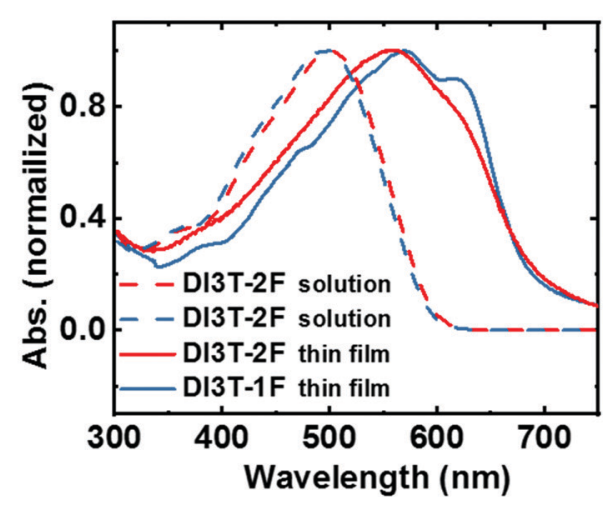

C

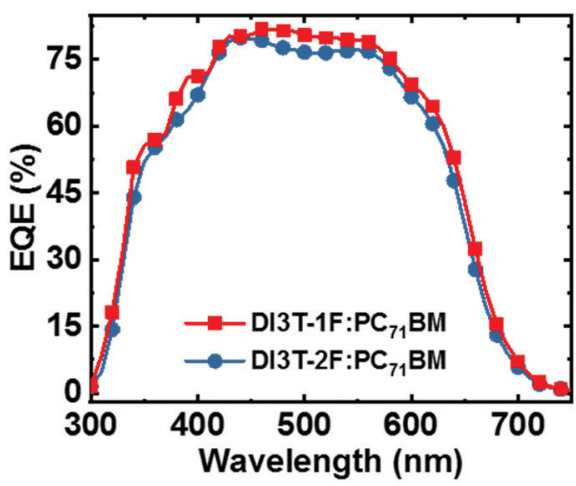

b

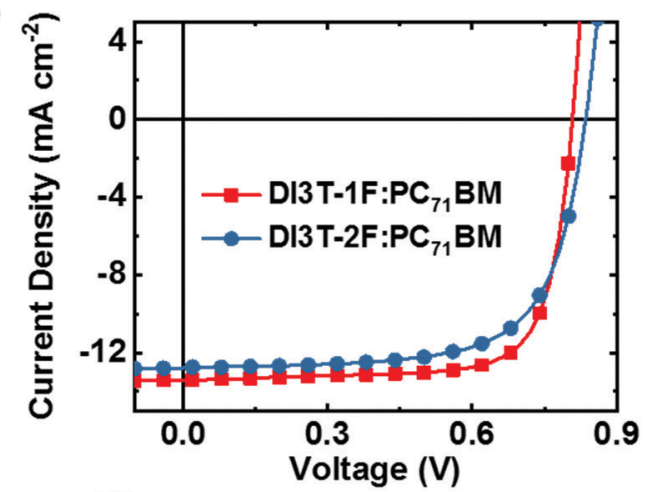

d

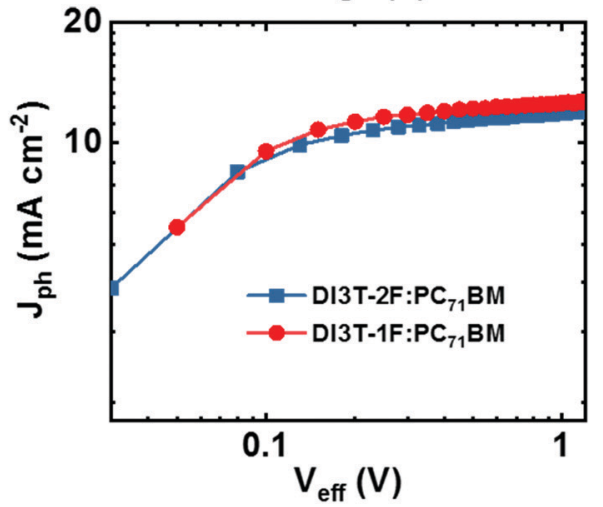

Fig. 1 (a) Absorption spectra of DI3T-F and DI3T-2F. (b) The J-V characteristics and (c) EQE spectra of the OSCs. (d) Photocurrent density ( $J_{\text {ph }}$ ) versus effective voltage $\left(V_{\text {eff }}\right)$ curves of the OSCs.

Table 1 Optical and electrochemical properties of DI3T-1F and DI3T-2F

\begin{tabular}{lllllll}
\hline & $\lambda_{\max }(\mathrm{sol})^{a}[\mathrm{~nm}]$ & $\lambda_{\max }(\mathrm{film})^{b}[\mathrm{~nm}]$ & $\lambda_{\text {onset }}(\mathrm{film})^{b}[\mathrm{~nm}]$ & $E_{\mathrm{g}}^{\text {opt }}[\mathrm{eV}]^{c}$ & $E_{\mathrm{HOMO}}{ }^{d}[\mathrm{eV}]$ & $E_{\mathrm{LUMO}}{ }^{d}[\mathrm{eV}]$ \\
\hline DI3T-F & 496 & 572 & 714 & 1.74 & -4.99 & -3.46 \\
DI3T-2F $^{24}$ & 498 & 561 & 717 & 1.73 & -5.15 & -3.42
\end{tabular}

${ }^{a}$ Solution absorption spectra $\left(1 \times 10^{-5} \mathrm{M}\right.$ in chloroform $) .{ }^{b}$ Absorption spectra of small molecular films on quartz glass. ${ }^{c}$ Optical bandgap derived from the absorption onset of small molecular films: $E_{\mathrm{g}}^{\mathrm{opt}}=1240 / \lambda_{\text {onset }} \mathrm{eV} .{ }^{d}$ Electrochemically determined $v s$. $\mathrm{Fc} / \mathrm{Fc}^{+}, E_{\mathrm{HOMO}}=-\left(E_{\mathrm{ox}}^{\mathrm{onset}}+4.8\right)$, $E_{\mathrm{LUMO}}=-\left(E_{\mathrm{red}}^{\text {onset }}+4.8\right)$.

from the increased $J_{\mathrm{sc}}$ and $\mathrm{FF}$. To further understand the improvement, we focused on the improvement of $J_{\mathrm{sc}}$ and FF from dual-fluorine to mono-fluorine in the end group next.

Firstly, we shone our light into the light-to-current conversion, which can be performed by external quantum efficiency (EQE) measurements. As shown in Fig. 1c, the DI3T-1F based devices show a slightly higher EQE value than those of DI3T-2F devices in all light response regions. In addition, the integrated $J_{\mathrm{sc}}$ value from the EQE spectrum for DI3T-1F:PC ${ }_{71} \mathrm{BM}\left(13.0 \mathrm{~mA} \mathrm{~cm}{ }^{-2}\right)$ is higher than that for DI3T-2F:PC ${ }_{71} \mathrm{BM}\left(12.4 \mathrm{~mA} \mathrm{~cm}{ }^{-2}\right)$. The calculated values showed around 5\% mismatch compared with the $J_{\mathrm{sc}}$ values obtained from the $J-V$ measurements. In addition, the charge carrier dynamics plays a critical role in the charge generation and collection. To investigate that, the photocurrent density $\left(J_{\mathrm{sc}}\right)$ as a function of the effective voltage $\left(V_{\text {eff }}\right)^{38}$ is plotted in Fig. 1 d. $J_{\mathrm{ph}}$ is defined as $J_{\mathrm{ph}}=J_{1}-J_{\mathrm{d}}$, where $J_{1}$ and $J_{\mathrm{d}}$ are the photocurrent densities under illumination and in the dark, respectively. $V_{\text {eff }}$ is defined as $V_{\text {eff }}=V_{\mathrm{o}}-V_{\mathrm{a}}$, where $V_{\mathrm{o}}$ is the voltage at which $J_{\mathrm{ph}}=0$ and $V_{\mathrm{a}}$ is the applied bias. When $V_{\text {eff }}$ arrived at $c a .0 .5 \mathrm{~V}$, the $J_{\mathrm{ph}}$ value could reach the saturation condition $\left(J_{\text {sat }}\right)$, which indicates that almost all mobile carriers are swept out by the high internal electric field and collected by the individual electrodes. The charge collection probability $P(E, T)$ could be assessed by the formula of $P(E, T)=J_{\mathrm{ph}} / J_{\mathrm{sat}}$. Under the short-circuited conditions, the $P(E, T)$ for DI3T-1F devices is 96.2\%, whereas the DI3T-2F shows a $P(E, T)$ of $93.5 \%$, suggesting a better charge collection probability in DI3T-1F devices.

The charge carrier mobilities of two binary blend films were measured by the space-charge limited current method (SCLC) with device structures of ITO/PEDOT:PSS/active layer/MoOx/Ag for holeonly devices and ITO/ZnO/active layer/Ca/Al for electron-only devices (shown in Fig. 2a and b). The hole and electron mobilities of DI3T2F:PC ${ }_{71}$ BM were $2.4 \times 10^{-4}$ and $1.03 \times 10^{-4} \mathrm{~cm}^{2} \mathrm{~V}^{-1} \mathrm{~s}^{-1}$ with $\mu_{\mathrm{h}} / \mu_{\mathrm{e}}$ ratio of 2.36, while in a DI3T-1F system, higher hole and electron mobilities of $4.04 \times 10^{-4}$ and $3.67 \times 10^{-4} \mathrm{~cm}^{2} \mathrm{~V}^{-1} \mathrm{~s}^{-1}$ were achieved with a much better balanced $\mu_{\mathrm{h}} / \mu_{\mathrm{e}}$ ratio of 1.11 .

Such higher and more balanced charge carrier mobilities in the DI3T-1F system could contribute to the much higher $J_{\mathrm{sc}}$ 
a

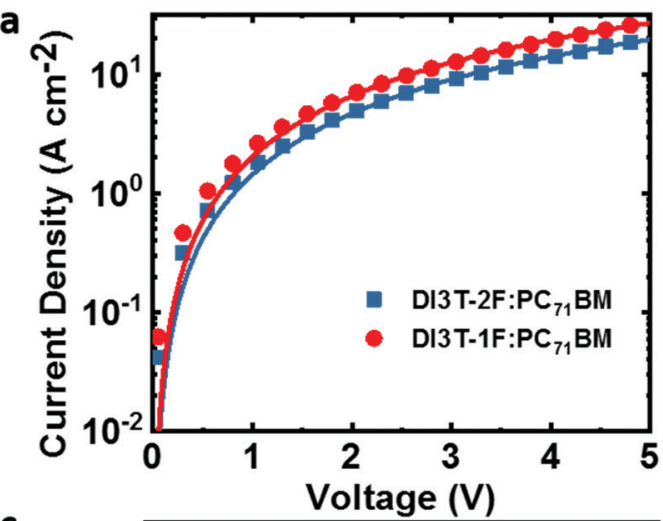

C

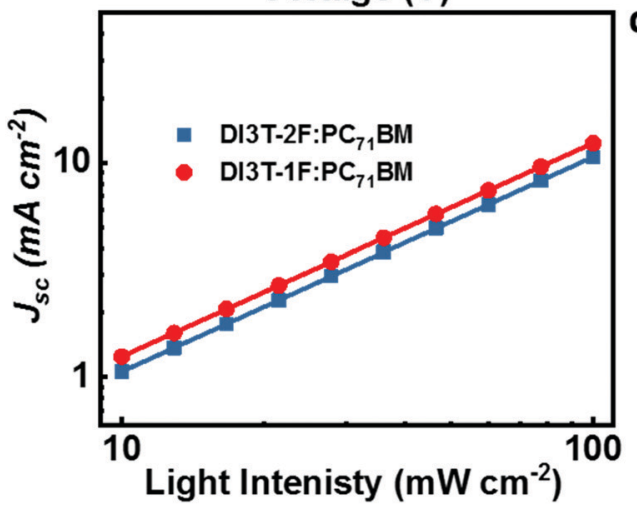

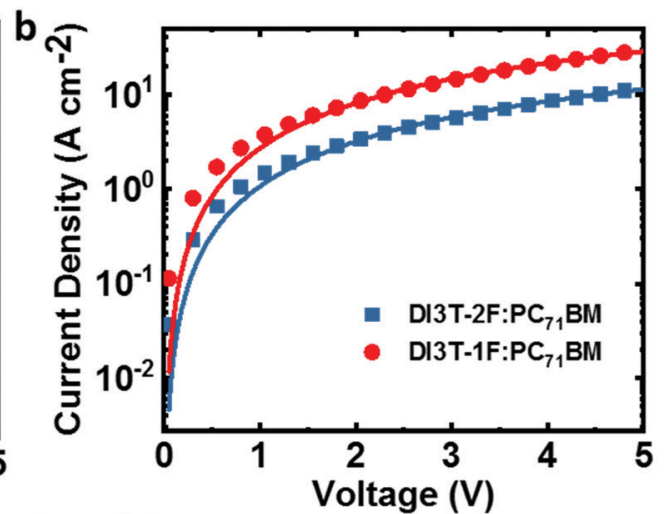

d

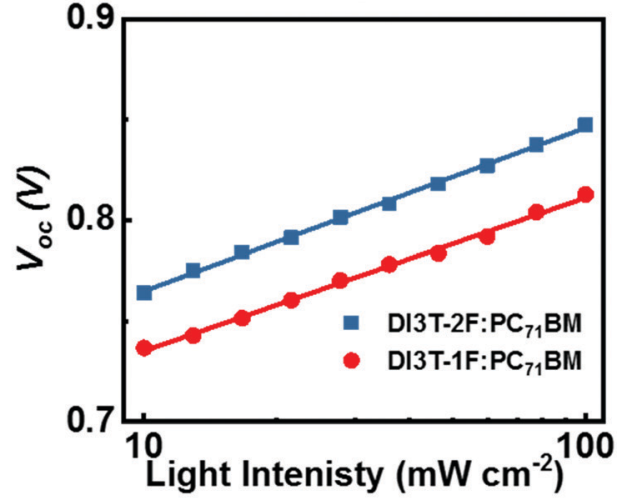

Fig. 2 ( $a$ and b) The dark current density versus voltage curves of the OSCs. (c) The plot of $J_{s c} v s$. light intensity of the OSCs. (d) The plot of $V_{\text {oc }}$ vs. light intensity of the OSCs.

and FF, which is consistent with a previous report. ${ }^{38 b}$ On the other hand, the bimolecular recombination process was investigated by measuring the dependence of $J_{\text {sc }}$ values on light intensity $\left(P_{\text {light }}\right)$, which can be expressed as a power-law formula $J_{\text {sc }} \propto\left(P_{\text {light }}\right)^{S}$, where $S$ close to 1 implies that the bimolecular recombination in negligible. As shown in Fig. 2c, both $S$ values of DI3T-1F and DI3T-2F are 0.99, indicating that the bimolecular recombination is not the main factor to contribute the improvement in performance. Furthermore, we investigate the $V_{\mathrm{oc}}$ as a function of light intensity to obtain the initial information on the trap-assisted recombination. In general, a slope of $k T / q$ is expected for solely bimolecular recombination, where $k$ is the Boltzmann constant, $q$ is elementary charge and $T$ is temperature, in the plot of $V_{\mathrm{oc}}$ versus the natural logarithm of the light intensity. In contrast, a signature of trap-assisted recombination is pronounced by an enhanced slope of $V_{\mathrm{oc}} v s$. light intensity $(2 k T / q)$. As shown in Fig. 2d, the DI3T-2F:PC ${ }_{71} \mathrm{BM}$ device delivers a slope of $1.31 \mathrm{kT} / \mathrm{q}$, suggesting the big potential of the recombination originated from traps. The trap-assisted recombination is drastically reduced in a DI3T-1F:PC ${ }_{71} \mathrm{BM}$ system (slope of $1.15 k T / q$ ), in agreement with the higher $\mathrm{FF}$ and better performance.

The bulk blend morphology of the two optimal blend films was examined by transmission electron microscopy (TEM). Normally, for the fullerene-based blend morphology, the dark regions are regarded as fullerene-rich domains, whereas the bright regions are believed to be small-molecule donor-rich domains. As shown in Fig. 3a and b, both DI3T-1F:PC ${ }_{71} \mathrm{BM}$ and a

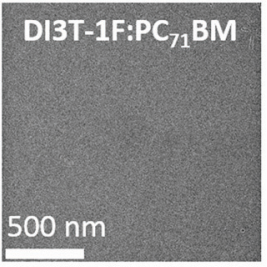

C
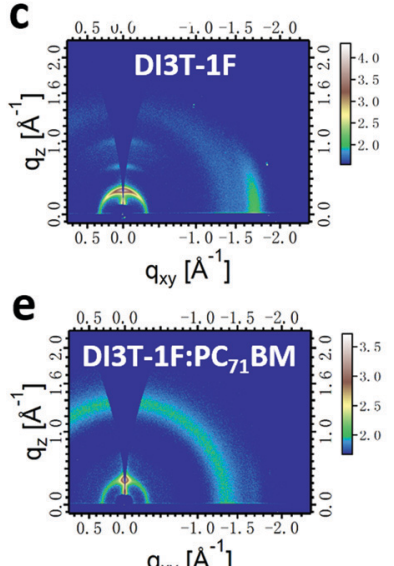

$$
q_{x y}\left[\AA^{-1}\right]
$$

Fig. 3 The TEM image of the blend film of (a) DI3T-1F:PC71BM and (b) DI3T-2F:PC71BM. The image of GIWAXS for the pristine films of (c) DI3T-1F and (d) DI3T-2F. The image of GIWAXS for the blend film of (e) DI3T-1F:PC71BM and (f) DI3T-2F:PC71BM. 
DI3T-2F: PC $_{71} \mathrm{BM}$ exhibit a homogeneous and intermixed blend morphology. However, comparing with the DI3T-2F system, the DI3T-1F: PC $_{71} \mathrm{BM}$ blend shows a smaller domain size, indicating a better miscibility of DI3T-1F and fullerene acceptors (which will be discussed below).

Grazing incidence wide-angle X-ray scattering (GIWAXS) measurements were performed to further understand the molecule crystallinity and orientation of the neat and blend films, which always generate a consequent impact on the device performance. $^{39,40}$ In detail, DI3T-1F and DI3T-2F featured a similar scattering pattern, with a distinct $\pi-\pi$ diffraction peak (010) in the in-plane (IP) direction and first-order (100), secondorder (200), and third-order (300) lamellar diffraction peaks in the out-of-plane (OOP) direction ${ }^{41}$ (shown in Fig. 3c and d). Further calculations from the IP and OOP profiles (Fig. S4, ESI $\dagger$ ) showed that the DI3T-2F shows a closer $\pi-\pi$ stacking distance (3.55 $\AA$ ) than that of DI3T-1F (3.62 $\AA$ ), indicating the higher ordered structure and preferential edge-on orientation, which is due to the stronger fluorination effect as there are more fluorine atoms in DI3T-2F. After blending with PC71BM, the original edge-on orientation has been weakened in both DI3T-1F and DI3T-2F small molecules. And more interestingly, there is a signal of (010) peak in the out-of-plane direction of the DI3T-1F:PC71BM blend film, showing an inclination to face-on orientation, which is important for a vertical transport device such as a solar cell. As reported in a previous report, ${ }^{42}$ the mixed face-on and edge-on orientation would enable high efficiency because of the establishment of 3D charge carrier transport pathways, so we believe that 3D pathways in DI3T-1F: $\mathrm{PC}_{71} \mathrm{BM}$ films implement efficient carrier transport, even in the film with thickness over $300 \mathrm{~nm} .^{43,44}$

To investigate the dependence of performance on the thickness of the photoactive layer from $150 \mathrm{~nm}$ to $300 \mathrm{~nm}$, devices with different thicknesses of active layers are fabricated, and Fig. 4a shows the variation of the solar cell performance as a function of the thickness of the photoacitive layer. For the DI3T-2F-based devices, the PCE drops dramatically from $7.32 \%$ to $3.62 \%$ with the thickness increasing from $\sim 150 \mathrm{~nm}$ to $\sim 300 \mathrm{~nm}$, which is mainly caused by the decreased $J_{\text {sc }}$ (from $12.8 \mathrm{~mA} \mathrm{~cm}^{-2}$ to $8.4 \mathrm{~mA} \mathrm{~cm} \mathrm{~cm}^{-2}$ ) and FF (from $68.5 \%$ to $51.6 \%$ ) (Table S1, ESI $\dagger$ ). Meanwhile, the PCE drops from $8.33 \%$ to $5.43 \%$ in the DI3T-1F system, with a very slight decrease of $J_{\mathrm{sc}}$ (from $13.6 \mathrm{~mA} \mathrm{~cm}^{-2}$ to $10.6 \mathrm{~mA} \mathrm{~cm}^{-2}$ ) (Table S2, ESI $\dagger$ ). These results show that the performance, especially $J_{\mathrm{sc}}$, in DI3T-1F is not as sensitive to the thickness of the active layers as for DI3T-2F.

As reported before in the OSCs, the difference in surface energies of the donors and acceptors plays a vital role in the device performance with increasing thickness of the active layers.

Therefore, we calculated the surface tensions of DI3T-1F, DI3T-2F and $\mathrm{PC}_{71} \mathrm{BM}$ by the contact angles of water (Fig. S6, ESI $\dagger$ ), ethylene glycol and benzylic alcohol on top of the corresponding film. The contact angle of the small molecules increases from DI3T-1F to DI3T-2F, indicating their enhanced hydrophobicity along with the increased amount of fluorine atoms in the end groups. Based on the contact angles, the surface tensions $(\gamma)$ of
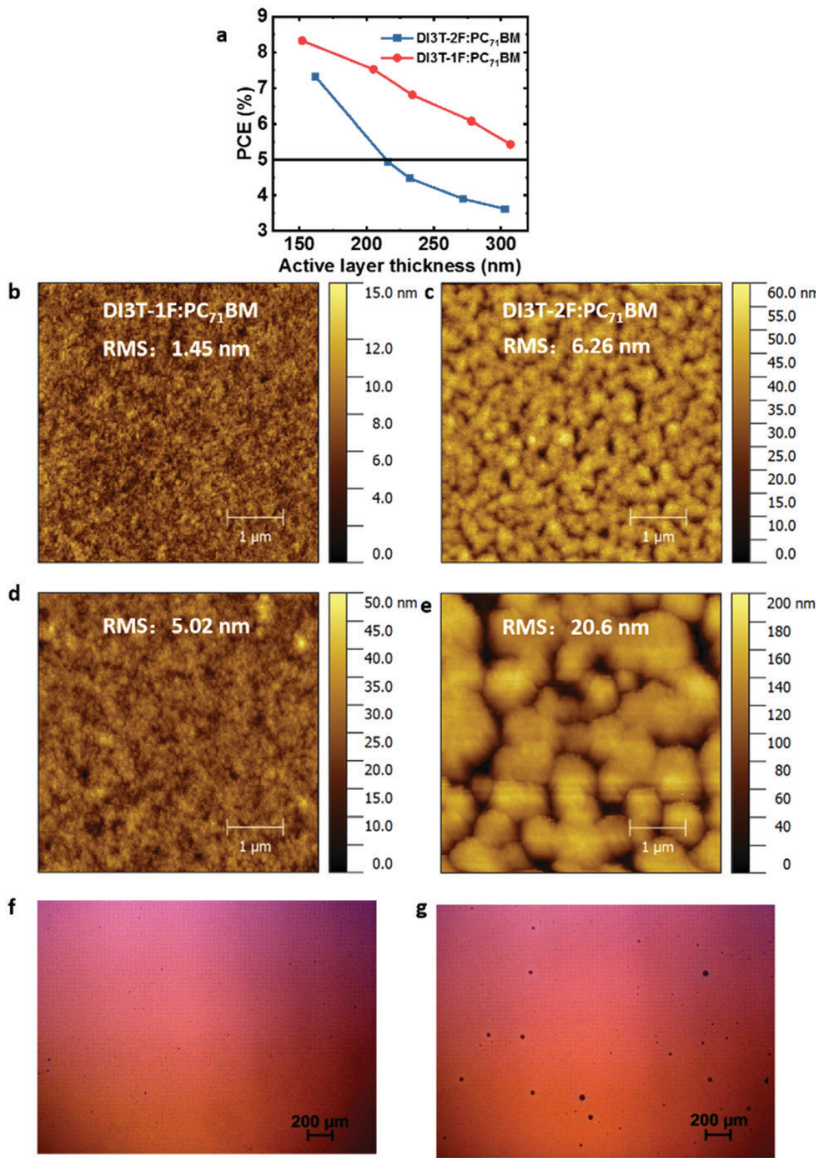

Fig. 4 (a) The performance of the DI3T-1F:PC71BM and DI3T-2F:PC71BM in different film thicknesses. The AFM topography of (b) DI3T-1F:PC71BM and (c) DI3T-2F:PC71BM with film thickness of $150 \mathrm{~nm}$. The AFM topography of (d) DI3T-1F:PC71BM and (e) DI3T-2F:PC71BM with film thickness of $300 \mathrm{~nm}$. The microscopy image of (f) DI3T-1F:PC71BM and (g) DI3T-2F: PC71BM with film thickness of $300 \mathrm{~nm}$.

them were obtained according to Wu's model, which are summarized in Table S3 (ESI $\dagger$ ). To afford an accurate comparison of the miscibility, the Flory-Huggins interaction parameter, ${ }^{45,46} \chi$ of the two blends was further evaluated based on the equation:

$$
\chi \propto\left(\sqrt{\gamma_{\text {donor }}}-\sqrt{\gamma_{\text {acceptor }}}\right)
$$

Therefore, the $\chi$ parameter decreases from DI3T-2F to DI3T-1F, indicating the enhanced miscibility with $\mathrm{PC}_{71} \mathrm{BM}$ along with the decrement of fluorine atoms. In addition, the solubilities of the SM donor in chloroform at room temperature were also tested. The solubility of DI3T-1F and DI3T-2F is $35 \mathrm{mg} \mathrm{mL}^{-1}$ and $11 \mathrm{mg} \mathrm{mL}^{-1}$, respectively. Notably, the higher solubility of SM in the processing solvent would delay the aggregation of the SM and promise more time for it to diffuse to form the blend network during the filmformation, especially in a thick active layer. ${ }^{47}$ To confirm this hypothesis, we utilized atomic force microscopy (AFM) measurement to characterize the surface morphology of the blend film with a thickness of $150 \mathrm{~nm}$ and $300 \mathrm{~nm}$, respectively. With one fluorine atom in the end group of DI3T-1F, the BHJ film shows a smooth surface morphology with a small root-mean-square 
(RMS) roughness of $1.61 \mathrm{~nm}$ (Fig. 4a), whereas in the DI3T-2F film the RMS roughness significantly increases to $6.26 \mathrm{~nm}$ (Fig. 4b) for a thickness of $\sim 150 \mathrm{~nm}$ of the active layer. Further increasing the thickness to $300 \mathrm{~nm}$, the DI3T-1F film maintains a smooth surface with RMS of $5.02 \mathrm{~nm}$ (Fig. 4c), whereas the DI3T-2F (Fig. 4d) film shows an RMS of $20.6 \mathrm{~nm}$, exhibiting a severely rough surface with strong aggregated domains, inducing the inefficient charge transport pathways throughout the thick films, ${ }^{48,49}$ which also strongly supports our strategy to reduce the aggregation of DI3T-2F by reducing the number of fluorine atoms from two to one in the end group. The surface images of DI3T-1F: $\mathrm{PC}_{71} \mathrm{BM}$ and DI3T-2F:PC ${ }_{71} \mathrm{BM}$ films with thickness over $300 \mathrm{~nm}$ were investigated by opical microscopy (Fig. 4e and f). There are many black dots in the DI3T-2F films, implying that there is severe aggregation of $\mathrm{PC}_{71} \mathrm{BM}$ and poor phase separation. ${ }^{50}$ Therefore, we believe that the lower surface tension difference between the donor and acceptor, and high solubility is crucial to achieve the desired morphologies for high performance of SMSCs with a thick photovoltaic layer.

\section{Conclusions}

In conclusion, we synthesized DI3T-1F with less fluorine atoms on the peripheral isatin unit and compared it to DI3T-2F as donors in a blend with $\mathrm{PC}_{71} \mathrm{BM}$ in thick organic solar cells. Both devices based on DI3T-1F and DI3T-2F demonstrate a very good tolerence for a thick active layer from $150 \mathrm{~nm}$ to $300 \mathrm{~nm}$. However, the devices based on DI3T-1F show a better balance of charge transport, morphology separation and less trap-assisted recombination, leading to a higher champion PCE of $8.33 \%$, which is $14 \%$ higher than that based on DI3T-2F (7.32\%) even with almost the same thickness of the active layer ( $c a .150 \mathrm{~nm})$. More interestingly, devices based on DI3T-1F with less fluorine show a better tolerence of thick active layers than that of DI3T-2F, and even with a thickness of $\sim 300 \mathrm{~nm}$, the PCE of the devices based on DI3T-1F is $5.43 \%$, which is about $50 \%$ higher than that of the devices based on DI3T-2F (3.62\%). The thick active layer is still one of the challenges for the whole organic photovoltaics community, so herein we believe it can be an efficient way to develop new materials for thick-layer organic solar cells by tuning the number of fluorines on the tails of the donors.

\section{Conflicts of interest}

There are no conflicts to declare.

\section{Acknowledgements}

Prof. G. Li acknowledges the general supported by the National Key R\&D Program of China (2017YFA0204704), the National Science Foundation of China (51773091, 61604069, and 61761136013), and the Natural Science Foundation of Jiangsu Province (BK20171465);
Prof A. K. Kyaw acknowledges general support by Thousand Talents Program of China and Shenzhen Municipal Science and Technology Innovation Committee and Shenzhen Peacock Team Project (No. KQTD2016030111203005).

Prof. D. Baran acknowledges the general support by KAUST Solar Center Competitive Fund (CCF) for financial support.

\section{Notes and references}

1 G. Yu, J. Gao, J. C. Hummelen, F. Wudl and A. J. Heeger, Science, 1995, 270, 1789-1791.

2 J. J. M. Halls, C. A. Walsh, N. C. Greenham, E. A. Marseglia, R. H. Friend, S. C. Moratti and A. B. Holmes, Nature, 1995, 376, 498-500.

3 J. Zhou, X. Wan, Y. Liu, Y. Zuo, Z. Li, G. He, G. Long, W. Ni, C. Li, X. Su and Y. Chen, J. Am. Chem. Soc., 2012, 134, 16345-16351.

4 Y. Lin, J. Wang, Z. G. Zhang, H. Bai, Y. Li, D. Zhu and X. Zhan, Adv. Mater., 2015, 27, 1170-1174.

5 B. Fan, D. Zhang, M. Li, W. Zhong, Z. Zeng, L. Ying, F. Huang and Y. Cao, Sci. China: Chem., 2019, 62, 746-752.

6 (a) S. D. Collins, N. A. Ran, M. C. Heiber and T.-Q. Nguyen, Adv. Energy Mater., 2017, 7, 1602242; (b) D. Baran, S. E. Ela, A. Kratzer, T. Ameri, C. J. Brabec and A. Hirsch, RSC Adv., 2015, 5, 64724-64730.

7 K. Gao, L. Li, T. Lai, L. Xiao, Y. Huang, F. Huang, J. Peng, Y. Cao, F. Liu, T. P. Russell, R. A. Janssen and X. Peng, J. Am. Chem. Soc., 2015, 137, 7282-7285.

8 B. Kan, M. Li, Q. Zhang, F. Liu, X. Wan, Y. Wang, W. Ni, G. Long, X. Yang, H. Feng, Y. Zuo, M. Zhang, F. Huang, Y. Cao, T. P. Russell and Y. Chen, J. Am. Chem. Soc., 2015, 137, 3886-3893.

9 K. Sun, Z. Xiao, S. Lu, W. Zajaczkowski, W. Pisula, E. Hanssen, J. M. White, R. M. Williamson, J. Subbiah, J. Ouyang, A. B. Holmes, W. W. Wong and D. J. Jones, Nat. Commun., 2015, 6, 6013.

10 L. Yuan, K. Lu, B. Xia, J. Zhang, Z. Wang, Z. Wang, D. Deng, J. Fang, L. Zhu and Z. Wei, Adv. Mater., 2016, 28, 5980-5985.

11 M. Li, K. Gao, X. Wan, Q. Zhang, B. Kan, R. Xia, F. Liu, X. Yang, H. Feng, W. Ni, Y. Wang, J. Peng, H. Zhang, Z. Liang, H.-L. Yip, X. Peng, Y. Cao and Y. Chen, Nat. Photonics, 2016, 11, 85-90.

12 B. Kan, H. Feng, H. Yao, M. Chang, X. Wan, C. Li, J. Hou and Y. Chen, Sci. China: Chem., 2018, 61, 1307-1313.

13 J. A. Love, C. M. Proctor, J. Liu, C. J. Takacs, A. Sharenko, T. S. van der Poll, A. J. Heeger, G. C. Bazan and T.-Q. Nguyen, Adv. Funct. Mater., 2013, 23, 5019-5026.

14 J. Miao, H. Chen, F. Liu, B. Zhao, L. Hu, Z. He and H. Wu, Appl. Phys. Lett., 2015, 106, 183302.

15 J. D. Zimmerman, X. Xiao, C. K. Renshaw, S. Wang, V. V. Diev, M. E. Thompson and S. R. Forrest, Nano Lett., 2012, 12, 4366-4371.

16 S. Chen, L. Yan, L. Xiao, K. Gao, W. Tang, C. Wang, C. Zhu, X. Wang, F. Liu, X. Peng, W.-K. Wong and X. Zhu, J. Mater. Chem. A, 2017, 5, 25460-25468.

17 J.-L. Wang, Z. Wu, J.-S. Miao, K.-K. Liu, Z.-F. Chang, R.-B. Zhang, H.-B. Wu and Y. Cao, Chem. Mater., 2015, 27, 4338-4348. 
18 J. Min, Y. N. Luponosov, N. Gasparini, L. Xue, F. V. Drozdov, S. M. Peregudova, P. V. Dmitryakov, K. L. Gerasimov, D. V. Anokhin, Z.-G. Zhang, T. Ameri, S. N. Chvalun, D. A. Ivanov, Y. Li, S. A. Ponomarenko and C. J. Brabec, J. Mater. Chem. A, 2015, 3, 22695-22707.

19 V. Piradi, X. Xu, Z. Wang, J. Ali, Q. Peng, F. Liu and X. Zhu, ACS Appl. Mater. Interfaces, 2019, 11, 6283-6291.

20 C. D. Wessendorf, A. Perez-Rodriguez, J. Hanisch, A. P. Arndt, I. Ata, G. L. Schulz, A. Quintilla, P. Bäuerle, U. Lemmer, P. Wochner, E. Ahlswede and E. Barrena,J. Mater. Chem. A, 2016, 4, 2571-2580.

21 Y. Huang, W. Wen, S. Mukherjee, H. Ade, E. J. Kramer and G. C. Bazan, Adv. Mater., 2014, 26, 4168-4172.

22 Y. Liu, C. C. Chen, Z. Hong, J. Gao, Y. M. Yang, H. Zhou, L. Dou, G. Li and Y. Yang, Sci. Rep., 2013, 3, 3356.

23 S. Chen, L. Xiao, X. Zhu, X. Peng, W.-K. Wong and W.-Y. Wong, Chem. Commun., 2015, 51, 14439.

24 S. Mukherjee, C. M. Proctor, G. C. Bazan, T.-Q. Nguyen and H. Ade, Adv. Energy Mater., 2015, 5, 1500877.

25 (a) X. Song, N. Gasparini, M. M. Nahid, H. Chen, S. M. Macphee, W. Zhang, V. Norman, C. Zhu, D. Bryant, H. Ade, I. McCulloch and D. Baran, A Highly Crystalline Fused-Ring n-Type Small Molecule for Non-Fullerene Acceptor Based Organic Solar Cells and Field-Effect Transistors, Adv. Funct. Mater., 2018, 28, 1802895; (b) C. Cui, X. Guo, J. Min, B. Guo, X. Cheng, M. Zhang, C. J. Brabec and Y. Li, Adv. Mater., 2015, 27, 7469-7475.

26 D. Corzo, K. Almasabi, E. Bihar, S. Macphee, D. Rosas-Villalva, N. Gasparini, S. Inal and D. Baran, Adv. Mater. Technol., 2019, 8, 1900040.

27 G. Zhang, K. Zhang, Q. Yin, X.-F. Jiang, J. Xin, W. Ma, H. Yan, F. Huang and Y. Cao, J. Am. Chem. Soc., 2017, 139, 2387-2395.

28 J. Lee, D. H. Sin, B. Moon, J. Shin, H. G. Kim, M. Kim and K. Cho, Energy Environ. Sci., 2017, 10, 247-257.

29 J. Huang, J. H. Carpenter, C.-Z. Li, J.-S. Yu, A. Ade and A. K.-Y. Jen, Adv. Mater., 2016, 28, 967-974.

30 S. Feng, C. Zhang, Y. Liu, Z. Bi, Z. Zhang, X. Xu, W. Ma and Z. Bo, Adv. Mater., 2017, 29, 1703527.

31 Y. Liu, M. Li, J. Yang, W. Xue, S. Feng, J. Song, Z. Tang, W. Ma and Z. Bo, Adv. Energy Mater., 2019, 9, 1901280.

32 M. Li, Y. Zhou, J. Zhang, J. Song and Z. Bo, J. Mater. Chem. A, 2019, 7, 8889-8896.

33 Y. Yang, K. Wang, G. Li, X. Ran, X. Song, N. Gasparini, Q. Q. Zhang, X. Lai, X. Guo, F. Meng, M. Du, W. Huang and D. Baran, Small, 2018, 14, e1801542.
34 C. J. Takacs, S. D. Collins, J. A. Love, A. A. Mikhailovsky, D. Wynands, G. C. Bazan, T. Q. Nguyen and A. J. Heeger, ACS Nano, 2014, 8, 8141-8151.

35 D. Xie, T. Liu, W. Gao, C. Zhong, L. Huo, Z. Luo, K. Wu, W. Xiong, F. Liu, Y. Sun and C. Yang, Sol. RRL, 2017, 1, 1700044. 36 X. Song, N. Gasparini, M. M. Nahid, S. H. K. Paleti, J.-L. Wang, H. Ade and D. Baran, Joule, 2019, 3, 846-857.

37 W.-Y. Tan, R. Wang, M. Li, G. Liu, P. Chen, X.-C. Li, S.-M. Lu, H. L. Zhu, Q.-M. Peng, X.-H. Zhu, W. Chen, W. C. H. Choy, F. Li, J. Peng and Y. Cao, Adv. Funct. Mater., 2014, 24, 6540-6547.

38 (a) S. Li, L. Ye, W. Zhao, X. Liu, J. Zhu, H. Ade and J. Hou, Adv. Mater., 2017, 29, 1704051; (b) A. K. K. Kyaw, D. H. Wang, C. Luo, Y. Cao, T.-Q. Nguyen, G. C. Bazan and A. J. Heeger, Adv. Energy Mater., 2014, 4, 1301469.

39 H. Yao, L. Ye, J. Hou, B. Jang, G. Han, Y. Cui, G. M. Su, C. Wang, B. Gao, R. Yu, H. Zhang, Y. Yi, H. Y. Woo, H. Ade and J. Hou, Adv. Mater., 2017, 29, 1700254.

40 S. Dai, F. Zhao, Q. Zhang, T. K. Lau, T. Li, K. Liu, Q. Ling, C. Wang, X. Lu, W. You and X. Zhan, J. Am. Chem. Soc., 2017, 139, 1336-1343.

41 H. Li, Y. Zhao, J. Fang, X. Zhu, B. Xia, K. Lu, Z. Wang, J. Zhang, X. Guo and Z. Wei, Adv. Energy Mater., 2018, 8, 1702377.

42 Y. Chang, Y. Chang, X. Zhu, X. Zhou, C. Yang, J. Zhang, K. Lu, X. Sun and Z. Wei, Adv. Energy Mater., 2019, 9, 1900190.

43 Z. Zhou, S. Xu, J. Song, Y. Jin, Q. Yue, Y. Qian, F. Liu, F. Zhang and X. Zhu, Nat. Energy, 2018, 3, 952-959.

44 B. Guo, X. Guo, W. Li, X. Meng, W. Ma, M. Zhang and Y. Li, J. Mater. Chem. A, 2016, 4, 13251-13258.

45 S. Kouijzer, J. J. Michels, M. van den Berg, V. S. Gevaerts, M. Turbiez, M. M. Wienk and R. A. Janssen, J. Am. Chem. Soc., 2013, 135, 12057-12067.

46 J. J. van Franeker, D. Hermida-Merino, C. Gommes, K. Arapov, J. J. Michels, R. A. J. Janssen and G. Portale, Adv. Funct. Mater., 2017, 27, 1702516.

47 G. Zhang, K. Zhang, Q. Yin, X. F. Jiang, Z. Wang, J. Xin, W. Ma, H. Yan, F. Huang and Y. Cao, J. Am. Chem. Soc., 2017, 139, 2387-2395.

48 T. Wang, X.-K. Chen, A. Ashokan, Z. Zheng, M. K. Ravva and J.-L. Brédas, Adv. Funct. Mater., 2018, 28, 1705868.

49 Q. Zhang, M. A. Kelly, N. Bauer and W. You, Acc. Chem. Res., 2017, 50, 2401-2409.

50 C. R. McNeill, H. Frohne, J. L. Holdsworth, J. E. Furst, B. V. King and P. C. Dastoor, Nano Lett., 2004, 4, 219-223. 